\title{
Growth rates of larval stage of Japanese anchovy Engraulis japonicus and environmental factors in the Kuroshio Extension and Kuroshio-Oyashio transition regions, western North Pacific Ocean
}

\author{
AKNORI TAKASUKA, AND ICHIRO AOKI \\ Graduate School of Agricultural and Life Sciences, The University of Tokyo, Bunkyo, Tokyo 113-8657, Japan \\ (aa07075@mail.ecc.u-tokyo.ac.jp)
}

KEYWORDS: growth rate, larvae, Japanese anchovy, otolith, Kuroshio, Oyashio, northward migration

\section{INTRODUCTION}

Recent studies of Japanese anchovy Engraulis japonicus have shown that they are distributed and spawn widely off the Pacific coast of eastern Honshu, Japan, with increasing stock size. Larvae are considered to be transported offshore and migrate, influenced by physically complicated process with warm and cold waters derived from the Kuroshio and Oyashio currents respectively. Survival mechanism during early life history stages in such offshore waters could be a missing link for population dynamics of Japanese anchovy. In this study, we examined the growth rates of larval stage of Japanese anchovy, which were collected in the Kuroshio Extension and Kuroshio-Oyashio transition regions, western North Pacific Ocean, by sagittal otolith microstructure analysis. Our objectives are to determine the principal environmental factor affecting larval growth rates and to find out a survival mechanism in relation to transport and migration of larvae.

\section{MATERIALS AND METHODS}

Larval Japanese anchovy of ca. 6-33 $\mathrm{mm}$ in standard length (SL) and environmental data were collected in the Kuroshio Extension and Kuroshio-Oyashio transition regions, in spring-summer 1996, 1997, 1999, and 2000 (Fig. 1). Larvae were captured mainly by a horizontal tow of a $160 \mathrm{~cm}$ diameter ORI (Ocean Research Institute) net with a mesh size of $0.69 \mathrm{~mm}^{1)}$ at the sea surface, and partly by a horizontal or oblique tow of a frame-type midwater trawl with a mouth area of $16 \mathrm{~m}^{2}$ and a mesh size of $8 \mathrm{~mm}$ at the depth of 15-30 m. Larval sampling was carried out during nighttime hours. Hydrographic data were obtained by CTD casts. Concurrently, prey organisms were collected by a vertical tow $(150 \mathrm{~m})$ of a $45 \mathrm{~cm}$ diameter NORPAC-twin net with two kinds of mesh size of 0.33 and $0.10 \mathrm{~mm}$.

Sagittal otoliths were dissected from individual larva and then daily ages were determined as the number of the daily growth increments plus 3 . Individual mean growth rates were calculated by dividing the SLs minus the hatch length by daily ages. Daily growth rate at each daily age was back-calculated for individual larva by biological intercept method assuming an allometric relationship between maximum otolith radius and $\mathrm{SL}^{2}{ }^{2}$

Stations were classified into two regions based mainly on the temperature at $100 \mathrm{~m}$ depth according to Odate. (Kuroshio Extension region: $\geqq 15^{\circ} \mathrm{C}$; Kuroshio-Oyashio transition region: $\left\langle 15^{\circ} \mathrm{C}\right.$ ). Prey abundance was estimated for each taxon as the number collected per tow in each mesh size of a NORPAC-twin net. The mean growth rates from hatching to capture, the 5-day mean growth rates (mean growth rates during every 5 daily ages), and the recent 3-day mean growth rates before capture were used to examine the relationship between growth and environmental factors and compared between regions and among stations.

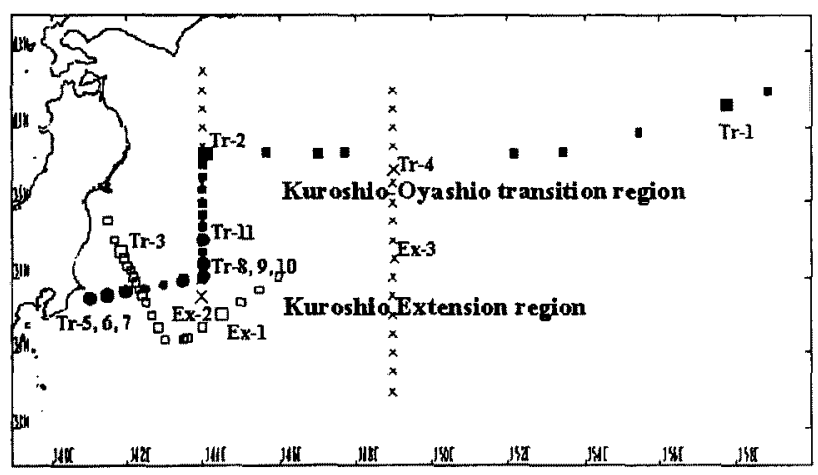

Fig1 Sampling areas and stations for larval Japanese anchovy and environmental data in the Kuroshio Extension (Ex) and Kuroshio-Oyashio

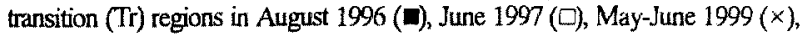
and April 2000 (O). Anonymous: hydrographic data only.

\section{RESULTS}

Sea surface temperature (SST) was relatively high $\left(>20^{\circ} \mathrm{C}\right.$ ) in the Kuroshio Extension region and tended to decline northward in the Kuroshio-Oyashio transition region (ca. $14-20^{\circ} \mathrm{C}$ ). But higher SST $\left(20.6^{\circ} \mathrm{C}\right)$ was observed at $\mathrm{Tr}-3$, 
probably associated with a warm core ring derived from the Kuroshio current.

Overall, the mean growth rates were positively correlated with SST (Fig. 2), especially from the Kuroshio-Oyashio transition region to the Kuroshio frontal region $\left(16-21^{\circ} \mathrm{C}\right)$. In the Kuroshio Extension region, SST seemed to excess the breakpoint at which the relation between SST and larval growth changes. Similar and slightly more distinct trends were shown in the recent 3-day mean growth rates before capture. On the other hand, variations in growth rates were not explained by prey abundance data. This would be owing mainly to lower growth rates in spite of higher potential prey availability in the Kuroshio-Oyashio transition region.

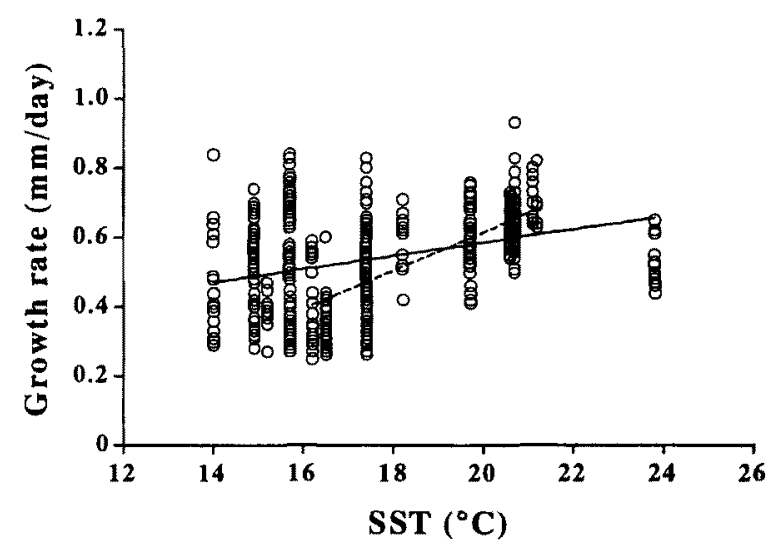

Fig. 2 Regressions of the mean growth rates on SST. Solid line in the SST range of 14.0-23.8: $y=0.21+0.02 x\left(N=617, R^{2}=0.11, p<0.001\right)$; dashed line in the SST range of 16.2-21.2: $y=-0.49+0.06 x\left(N=364, R^{2}=0.48, p<0.001\right)$.

Back-calculated daily growth rates were relatively consistent at higher level in the Kuroshio Extension region. Contrastively, the marked decreases in growth rates with daily age were generally shown in the Kuroshio-Oyashio transition region in early spring (Fig. 3). Such trends were confirmed in the temporal changes when data were pooled by days before capture (i.e. real time). On the other hand, the growth rates observed in summer (Tr-1) and at $\mathrm{Tr}-3$ were comparable to those in the Kuroshio Extension region.

\section{DISCUSSION}

A part of the larval Japanese anchovy hatching in the coastal side of the Kuroshio current would enter into the Kuroshio Extension region ${ }^{4)}$ and could be transported to the offshore waters during larval stage ${ }^{5}$. Subsequently, they are assumed to migrate northward into the Kuroshio-Oyashio transition region ${ }^{4}$. The consistent higher level of growth rates in the Kuroshio Extension region indicated that offshore transport of larvae by the Kuroshio Extension is unlikely to affect larval survival potential if to the eastern limit of $149^{\circ} \mathrm{E}$.

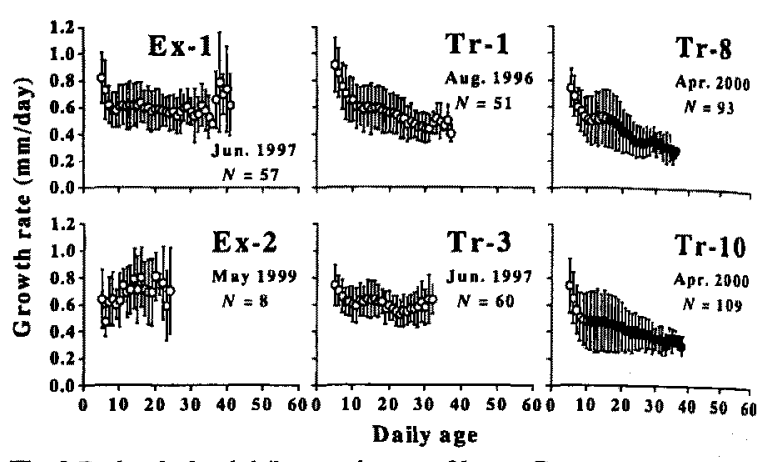

Fig. 3 Back-calculated daily growth rates of larvae. Data were pooled by daily age. Mean \pm SD shown at each daily age with at least 3 back-calculated data available. Solid circle means that growth rates were significantly lower in the Kuroshio-Oyashio transition region than in the Kuroshio Extension region (Ex-I, 2 , and 3 pooled) in comparison of the 5-day mean growth rates by Sheffe's tests.

Sea temperature was shown to be the principal environmental factor affecting larval growth rates and observed to decline northward in these regions. In addition, SST is not expected to decline temporally in this season. Therefore, the temporal decreases shown in the growth rate histories are considered to be a consequence of northward migration of larvae. The larvae captured in the Kuroshio-Oyashio transition regions in early spring had typically experienced temporal decreases in growth rates, which suggested their hasty northward migration. However, growth rates were higher in summer and at the station associated with a warm core ring in June. Growth rates had direct impacts on vulnerability to predation for larval anchovy (Takasuka A, Aoki I, Mitani I, unpubl. data, 2001). Thus, the timing of northward dispersal and migration would influence larval survival potential and operate as the trigger for mortality during early life history stages.

\section{REFERENCES}

1. Omori M. A $160-\mathrm{cm}$ opening-closing plankton net. $\mathrm{l}$. Description of the gear. J Oceanogr Soc Japan. 1965; 21: 212-220.

2. Watanabe Y, Kuroki T. Asymptotic growth trajectories of larval sardine (Sardinops melanostictus) in the coastal waters off westem Japan. Mar. Biol. 1997; 127: 369-378.

3. Odate $\mathrm{K}$. Zooplankton biomass and its long-term variation in the westem North Pacific Ocean, Tohoku Sea Area, Japan. Bull. Tohoku Nat. Fish. Res. Inst. 1994; 56: 115-173.

4. Aoki I, Miyashita K Dispersal of larvae and juveniles of Japanese anchovy Engraulis japonicus in the Kuroshio Extension and Kuroshio-Oyashio transition regions, westem North Pacific Ocean. Fish Res. 2000; 49: 155-164.

5. Takahashi M, Watanabe $\mathrm{Y}$, Kinoshita $\mathrm{T}$, Watanabe C. Growth of larval and early juvenile Japanese anchovy, Engraulis japonicus, in the Kuroshio-Oyashio transition region. Fish Oceanogr. 2001; 10: 235-247. 